\title{
Could infarct location predict the long-term functional outcome in childhood arterial ischemic stroke?
}

\author{
¿Puede la localización del infarto predecir el resultado funcional a largo plazo en el ictus \\ isquémico arterial pediátrico?
}

Mauricio López-Espejo', Marta Hernández-Chávez

\begin{abstract}
Objective: To explore the influence of infarct location on long-term functional outcome following a first-ever arterial ischemic stroke (AIS) in non-neonate children. Method: The MRIs of 39 children with AIS (median age 5.38 years; $36 \%$ girls; mean follow-up time 5.87 years) were prospectively evaluated. Infarct location was classified as the absence or presence of subcortical involvement. Functional outcome was measured using the modified Rankin scale (mRS) for children after the follow-up assessment. We utilized multivariate logistic regression models to estimate the odds ratios (ORs) for the outcome while adjusting for age, sex, infarct size and middle cerebral artery territory involvement (significance $<0.05)$. Results: Both infarcts $\geq 4 \%$ of total brain volume (OR 9.92; $\mathrm{Cl} 1.76-55.9 ; \mathrm{p} 0.009)$ and the presence of subcortical involvement (OR 8.36; Cl 1.76 - 53.6; p 0.025) independently increased the risk of marked functional impairment (mRS 3 to 5). Conclusion: Infarct extension and location can help predict the extent of disability after childhood AIS.
\end{abstract}

Keywords: stroke; disability; cerebrovascular disorders; cerebral infarction

\section{RESUMEN}

Objetivo: Para explorar la influencia de la localización del infarto sobre los resultados funcionales a largo plazo después de un primer ictus isquémico arterial (IIA) en niños posterior a la edad neonatal. Métodos: Se evaluaron de forma prospectiva imágenes por RM de 39 niños con IIA (mediana de edad:5,38 años;36\% niñas; seguimiento promedio:5,87 años). La localización del infarto fue clasificada como ausencia o presencia de compromiso subcortical. El resultado funcional fue medido utilizando la escala modificada de Rankin (mRS) para niños en una evaluación al final del seguimiento. Utilizamos modelos de regresión logística multivariada para estimar los odds ratios (ORs) para el resultado ajustado para la edad, sexo, tamaño del infarto y compromiso del territorio vascular de la arteria cerebral media (significancia $<0,05)$. Resultados: Tanto el tamaño del infarto > 4\% del volumen encefálico total (OR 9,92; IC 1,76-55,9; p 0,009) como la presencia de compromiso subcortical (OR 8,36; IC 1,76-53,6; p 0,025) incrementaron independientemente el riesgo de presentar marcado compromiso funcional (mRS 3 a 5). Conclusión: La extensión y localización del infarto pueden ayudar a predecir la magnitud de la discapacidad posterior a un IIA durante la niñez.

Palabras clave: accidente cerebrovascular; trastornos cerebrovasculares; infarto cerebral

Arterial ischemic stroke (AIS) is the most prevalent cerebrovascular disease encountered in children beyond the newborn period, with an estimated annual incidence of 2.4/100,000 persons ${ }^{1}$. Even though the developing brain possesses remarkable structural and functional plasticity in response to injury, at least half of the children who have suffered an AIS have persistent neurological impairment ${ }^{2,3,4,5}$. Additionally, the mortality rate has remained unchanged for at least the past 15 years (7-28\%) and is associated with significant age and ethnic variations ${ }^{2,5,6}$.
Research concerning prognosis after childhood AIS is mainly focused on short-term outcome, and only a few studies have examined the impact of clinical features on the development of long-term neurologic impairment. The initial stroke severity and one-year functional status were the strongest predictors of long-term outcome in two larger series ${ }^{5,7}$, but the possibility that radiological features in MRIs may be risk factors for functional and survival outcomes has not been evaluated sufficiently in children ${ }^{8}$.

${ }^{1}$ Pontificia Universidad Católica de Chile, Escuela de Medicina, Unidad de Neurología, División de Pediatría, Chile.

Correspondence: Mauricio López-Espejo; Unit of Neurology. Division of Pediatrics. School of Medicine. Pontificia Universidad Católica of Chile. Lira 85, Postal: 6510273 Santiago Chile; E-mail:mlopeze@med.puc.cl 
While studies of newborns with ischemic stroke have revealed the extraordinary value of the site and size of the lesion for motor and cognitive outcome ${ }^{9,10}$, research in older children exploring the influence of infarct characteristics on the longterm functional outcome is lacking and, except for the size of the lesion, these associations have not been fully established ${ }^{11,12,13}$.

Our purpose in the present study was to explore the influence of the infarct location, particularly subcortical involvement, on functional outcome in a cohort of children who were followed for at least four years after the occurrence of a first, isolated, supratentorial AIS. We hypothesized that the influence of stroke location on the outcome mentioned above is significant.

\section{METHODS}

\section{Study design and participants}

We undertook a prospective study of a cohort involving 39 consecutive patients who suffered a first, isolated, supratentorial AIS during childhood. The participants were enrolled in the study while hospitalized at the Pontificia Universidad Católica of Chile's Clinical Hospital between January 2003 and July 2012. We included all patients with a neurologic deficit of acute onset, and MRI showing an isolated parenchymal infarct conforming to known arterial territory and corresponding to clinical manifestations, experienced between the ages of 29 days and 18 years ${ }^{14}$. To avoid factors possibly confounding the prognosis, we excluded patients with bilateral, multiple, infratentorial or watershed infarcts, previous cerebrovascular disease (including, presumed perinatal stroke and cerebral sinovenous thrombosis ${ }^{15}$ ), concomitant hypoxic-ischemic encephalopathy, associated disorder with neurologic impairment at the time of the stroke, and functional impairment before the acute event. This study was approved by the institutional ethics committee and written informed parental consent was obtained.

\section{Data collection}

A pediatric neurologist filled out a standardized data collection form during the hospital stay. This document enabled us to collect information about each patient's clinical picture at the onset of symptoms, underlying conditions, and neurologic features from neuroimages. Outcome data was collected with a form evaluating functional impairment (according to the modified Rankin scale (mRS) for children ${ }^{5,16}$ ) and abnormalities on the neurologic examination. These measures were applied by a pediatric neurologist during an outpatient appointment or home visit four to eight years after the index stroke. Marked functional impairment, as in a previous study ${ }^{5}$, was defined as neurologic deficits interfering with daily life activities (mRS score 3 to 5). All information was entered into a database, corrected according to a review of medical and neuroimaging records, and enrolled according to the institutional protocols.
Imaging analysis

The MRI studies were performed in all patients within 36 hours after symptom onset and were repeated if new neurologic signs or symptoms appeared. Vascular imaging was available in 21 children and was performed within three weeks. All MRI sequences (diffusion weighted image, fluidattenuated inversion recovery, double inversion recovery and $\mathrm{T} 1$ with gadolinium, using $1.5 \mathrm{~T}$ with $5 \mathrm{~mm}$ thick slices, and $2.5 \mathrm{~mm}$ separation between cuts) were evaluated by a radiologist and subsequently reviewed by two physicians (a radiologist, and a pediatric neurologist) together.

Lesion and whole brain (cerebral hemispheres, brainstem, cerebellum, and ventricles) volumes were measured by manual segmentation using "NIH Image J" public domain software available on the National Institute of Health homepage. This method was applied to diffusion-weighted images obtained at the onset of the illness. The lesion size was expressed as a percentage of total brain volume, to adjust for changes in the brain volume with age, and was classified into large infarct: $\geq 4 \%$ of total brain volume, and small infarct: $<4 \%$ of total brain volume, in order to compare with previous studies ${ }^{13}$.

The infarct location was classified into two categories based on the absence or presence of a subcortical involvement infarct (basal ganglia, thalamus, internal capsule and centrum semiovale) with or without cortical ischemia. The involvement of the anterior cerebral artery, middle cerebral artery, and posterior cerebral artery territories were assessed.

\section{Data analysis}

The IBM SPSS Statistics version 22 software (IBM Corp., Somers, NY, USA) was used to identify differences in study variables between children admitted with AIS with and without subcortical infarcts, applying Fisher's exact test and the $t$-test for categorical and continuous variables, respectively. Three logistic binary regression models were created to identify the association between (1) subcortical involvement, (2) large infarcts, and (3) middle cerebral artery infarcts, and the odds of long-term functional impairment. These models were adjusted for age, stroke location, infarct size and middle cerebral artery territory involvement. A P-value of $<0.05$ was considered statistically significant.

\section{RESULTS}

\section{Sample characteristics}

Of 42 children who met the study's inclusion criteria, three could not be contacted (7.14\%). Among the 39 patients included in the study, 14 were girls $(35.9 \%)$ while 25 were boys $(64.1 \%)$. The median age at the time of stroke was 5.38 years (interquartile range, 0.49-9.91). Seven children died before outcome assessment (17.9\%); their mean survival time was 8.3 months (range, four days to 2.3 years), the causes of death were stroke (two patients), cardiac disease 
(two patients), leukemia, primary intracranial tumor (discovered five months after the stroke) and a systemic infection (one of each). Thirty-two children with a follow-up duration ranging between 4.2 and 8.72 years (mean 5.87 years) were considered for an outcome assessment. Baseline demographics, clinical features and radiological variables of the children are summarized in Table 1. There were no detected cases of either hemorrhagic transformation of infarction or intracranial hemorrhage in the cohort.

\section{Functional outcome}

For the neurological evaluation, marked functional impairment (mRS score 3-5) was found in 10 children (25.7\%), severe spastic hemiplegia in seven and profound cognitive impairment and mild spastic hemiplegia in three. Seventeen patients had mild spastic hemiplegia (43.6\%), which was not functionally limiting (mRS score 1), and five children had normal functionality (12.8\%).

After adjusting for age, arterial distribution and lesion size, a significantly larger proportion of children with marked functional impairment displayed subcortical infarcts (OR 8.36; CI 1.76-53.6; p 0.025) on MRI, compared to the group of survivors without marked impairment. We also found a positive correlation between the lesion size and adverse outcome (OR 9.92; CI 1.76-55.9; p 0.009). Table 2 summarizes the associations between radiological variables and the outcomes.

\section{DISCUSSION}

The primary goal of this study was to explore whether the lesion location could predict the occurrence of an adverse functional outcome in pediatric patients beyond the newborn period following a first AIS; in this regard, the main finding of our study was that in this cohort of Chilean children with an isolated supratentorial infarct, there was an association between the subcortical location of the stroke and the presence and severity of long-term functional impairment.

Research in children with perinatal AIS has documented the relationship between basal ganglia and thalamic injury and altered cognitive outcome ${ }^{17}$, but ours is the first study that strongly associates subcortical lesions with functional impairment in older children. This finding is in contrast to previous studies, which showed that combined cortical and

Table 1. Demographics, identified etiologies, and radiological features of children with arterial ischemic stroke with and without an isolated subcortical infarct (Pontificia Universidad Católica of Chile's Clinical Hospital: 2003 - 2012).

\begin{tabular}{|c|c|c|c|}
\hline Variables & With subcortical infarct & Without subcortical infarct & $p$-value \\
\hline Overall, n (\%) & $26(67)$ & $13(33)$ & \\
\hline \multicolumn{4}{|l|}{ Demographics and treatment } \\
\hline Female, n (\%) & $11(42.3)$ & $3(23.1)$ & 0.304 \\
\hline Male, n (\%) & $15(57.7)$ & $10(76.9$ & 0.304 \\
\hline Age in years, mean (SD) & $6.16(5.37)$ & $3.83(4.20)$ & 0.148 \\
\hline Time of follow-up, mean (SD) & $4.95(2.69)$ & $4.93(1.98)$ & 0.982 \\
\hline Anticoagulant treatment, n (\%) & $19(73.1)$ & $10(76.9)$ & 0.999 \\
\hline \multicolumn{4}{|l|}{ Clinical presentation } \\
\hline GCS $<12, \mathrm{n}(\%)$ & $12(46.2)$ & $8(61.5)$ & 0.501 \\
\hline Headache, n (\%) & $5(19.2)$ & $2(15.4)$ & 1.000 \\
\hline Acute seizures, n (\%) & $9(34.6)$ & $5(38.5)$ & 1.000 \\
\hline Focal neurologic deficits, n (\%) & $20(76.9)$ & $9(69.2)$ & 0.704 \\
\hline \multicolumn{4}{|l|}{ Stroke etiology } \\
\hline Cardioembolic, n (\%) & $11(42.3)$ & $6(46.2)$ & 1.000 \\
\hline Arteriopathy, n (\%) & $5(19.2)$ & $2(15.4)$ & 1.000 \\
\hline Thrombophilia*, n (\%) & $2(7.7)$ & $1(7.7)$ & 1.000 \\
\hline Other etiology**, n (\%) & $3(11.5)$ & $3(23.1)$ & 0.380 \\
\hline Multifactorial, n (\%) & $3(11.5)$ & $0(0)$ & 0.538 \\
\hline Undetermined, n (\%) & $5(19.2)$ & $2(15.4)$ & 1.000 \\
\hline \multicolumn{4}{|l|}{ Stroke-related radiological variables } \\
\hline Right sided, n (\%) & $15(57.7)$ & $7(53.8)$ & 1.000 \\
\hline ACA territory, n (\%) & $11(42.3)$ & $3(23.1)$ & 0.304 \\
\hline MCA territory, n (\%) & $11(42.3)$ & $7(53.8)$ & 0.520 \\
\hline PCA territory, n (\%) & $4(15.4)$ & $3(23.1)$ & 0.666 \\
\hline Large lesion ( $\geq 4 \%$ TBV), n (\%) & $17(65.4)$ & $6(46.2)$ & 0.312 \\
\hline Stroke recurrence, $\mathrm{n}(\%)$ & $3(13)$ & $1(8.3)$ & 1.000 \\
\hline
\end{tabular}


Table 2. Effect of stroke-related radiological features on long-term functional outcome.

\begin{tabular}{|c|c|c|c|c|c|c|}
\hline \multirow{2}{*}{ Variable } & \multicolumn{2}{|c|}{ Univariate } & \multicolumn{2}{|c|}{ Multivariate* } & \multicolumn{2}{|c|}{ Multivariate** } \\
\hline & OR $(95 \% \mathrm{Cl})$ & $\mathrm{p}$-value & OR $(95 \% \mathrm{Cl})$ & $\mathrm{p}$-value & OR $(95 \% \mathrm{Cl})$ & $\mathrm{p}$-value \\
\hline \multicolumn{7}{|l|}{ Subcortical involvement } \\
\hline Minimal or absent impairment & Reference & & Reference & & Reference & \\
\hline Marked impairment & $6.5(1.2-36.6)$ & 0.03 & $7.78(1.3-47.9)$ & 0.02 & $9.33(1.2-72.3)$ & 0.03 \\
\hline \multicolumn{7}{|l|}{ Large lesion ( $\geq 4 \%$ TVB) } \\
\hline Minimal or absent impairment & Reference & & Reference & & Reference & \\
\hline Marked impairment & $7.43(1.6-35.5)$ & 0.01 & $7.54(1.6-36.3)$ & 0.01 & $7.64(1.3-43.4)$ & 0.02 \\
\hline \multicolumn{7}{|l|}{ MCA infarct } \\
\hline Minimal or absent impairment & Reference & & Reference & & Reference & \\
\hline Marked impairment & $1.71(0.4-6.6)$ & 0.44 & $1.77(0.4-7.2)$ & 0.42 & $2.75(0.5-16.4)$ & 0.27 \\
\hline
\end{tabular}

subcortical lesions are significantly more likely to result in cognitive impairment in the long term compared to isolated cortical or subcortical infarctions ${ }^{18,19}$. One study even associated the presence of isolated subcortical lesions with a favorable outcome ${ }^{20}$. Although the study criteria could explain these differences, the leading cause of these results may lie in the size of the stroke, since combined lesions are likely to be the largest, as well. Consistent with research in pediatric populations, our results showed that patients who had large infarcts were much more likely to develop a long-term disability. Thus, we performed a logistic regression analysis to adjust for confounding variables, including stroke size, allowing us to identify independent predictors of the outcome. In the results section, we showed that there were no significant differences between children with or without subcortical involvement with respect to age, sex, underlying conditions, initial clinical manifestations or other radiological features.

The role of the subcortical nuclei in motor regulation and cognitive functions has been well established ${ }^{21}$. Subcortical pathways reciprocally interconnect neuronal activity of an important and diverse set of cerebral cortical areas with the basal ganglia and thalamus. It is noteworthy that the functional organization of these circuits changes across development, allowing the improvement of motor and cognitive behaviors ${ }^{22}$. However, the molecular mechanism implicated in these changes is particularly vulnerable to injury in energy failure $^{23}$. Thus, impaired neural plasticity due to ischemia in the developing brain, particularly during critical periods, may be the pathophysiology basis of functional deterioration in these patients.

It is a unique characteristic of our study that we evaluated stroke features in a South American pediatric population and their impact on long-term functional outcomes. The results are characterized by a high prevalence of poor outcomes following pediatric AIS; these data are consistent with those of previous studies that included other geographic groups ${ }^{2,18,24,25}$.

The limitations of this study must be considered when reviewing these results. Firstly, this is a single center study with a relatively small sample size. The prevalence of adverse outcomes found in our cohort may not accurately reflect our country's statistics; thus, future research should include tertiary centers across several regions to obtain results that may be generalized. Furthermore, our study population included many children with heart diseases and relatively few with CNS arteriopathies; this was probably because the study was conducted in a referral center for the surgical resolution of complex congenital heart diseases, as well as because there was a relative lack of vascular imaging studies undertaken at the time of diagnosis.

The strengths of the study lie in its clear selection criteria, controlled for confounding variables, prospective recruitment, and uniform evaluation. This study has also contributed to an increase in the understanding of the long-term outcomes of stroke in children. Finally, the scale used to assess functional outcome does not include any direct measure of cognitive function or self-perceived quality of life; thus, we believe that future research focused on these outcomes may result in the development of a risk scoring system for the development of neurologic disability following an AIS.

In conclusion, early identification of children at increased risk for impairment would allow for early interventions and could be useful in reducing permanent disability. In this regard, the size and subcortical involvement of the infarcts are potential predictors of adverse outcome following an isolated supratentorial stroke.

\section{Acknowledgment}

The authors thank Dr. Isidro Huete, Dr. Escobar-Henríquez (Raúl), Dr. Mesa-Latorre (Tomás), Dr. Núñez-Farias (Alicia), Dr. Beytía-Reyes (María), Dr. Acevedo-Gallinato (Keryma), Dr. Ávila-Smirnov (Daniela), Dr. Samsó-Zepeda (Catalina), and Dr. Arriaza-Ortiz (Manuel) for their valuable contribution to patient recruitment, and Pontifical University Catholic of Chiles Clinical Hospital staff and participants for their important contributions to this work. 
1. Agrawal N, Johnston SC, Wu YW, Sidney S, Fullerton HJ. Imaging data reveal a higher pediatric stroke incidence than prior Us estimates. Stroke. 2009;40(11):3415-21. https://doi.org/10.1161/STROKEAHA.109.564633

2. Veber GA, MacGregor D, Curtis R, Mayank S. Neurologic outcome in survivors of childhood arterial ischemic stroke and sinovenous thrombosis. J Child Neurol. 2000;15(5):316-24. https://doi.org/10.1177/088307380001500508

3. Ganesan V, Hogan A, Shack N, Gordon A, Isaacs E, Kirkham FJ. Outcome after ischaemic stroke in childhood. Dev Med Child Neurol. 2000;42(7):455-61. https://doi.org/10.1017/S0012162200000852

4. De Schryver EL, Kappelle LJ, Jennekens-Schinkel A, Boudewyn Peters AC. Prognosis of ischemic stroke in childhood: a long-term follow-up study. Dev Med Child Neurol. 2000;42(5):313-8. https://doi.org/10.1017/S0012162200000554

5. Goeggel Simonetti B, Cavelti A., Arnold M., Bigi S, Regényi M, Mattle HP et al. Long-term outcome after arterial ischemic stroke in children and young adults. Neurology. 2015;84(19):1941-7. https://doi.org/10.1212/WNL.0000000000001555

6. Fullerton HJ, Elkins JS, Johnston SC. Pediatric Stroke Belt: geographic variation in stroke mortality in US children. Stroke. 2004;35(7):1570-3. https://doi.org/10.1161/01.STR.0000130514.21773.95

7. Elbers J, Veber G, Pontigon AM, Moharir M. Long-term outcomes of pediatric ischemic stroke in adulthood.J Child Neurol. 2014;29(6):782-8. https://doi.org/10.1177/0883073813484358

8. Greenham M, Gordon A, Anderson V, Mackay MT. Outcome in childhood stroke. Stroke. 2016;47(4):1159-64. https://doi.org/10.1161/STROKEAHA.115.011622

9. Boardman JP, Ganesan V, Rutherford MA, Saunders DE, Mercuri E, Cowan F. Magnetic resonance image correlates of hemiparesis after neonatal and childhood middle cerebral artery stroke. Pediatrics. 2005;115(2):321-6. https://doi.org/10.1542/peds.2004-0427

10. Westmacott R, Askalan R, MacGregor D, Anderson P, Deveber G. Cognitive outcome following unilateral arterial ischaemic stroke in childhood: effects of age at stroke and lesion location. Dev Med Child Neurol. 2010;52(4):386-93. https://doi.org/10.1111/j.1469-8749.2009.03403.x

11. Ganesan V, Ng V, Chong WK, Kirkham FJ, Connelly A. Lesion volume, lesion location, and outcome after middle cerebral artery territory stroke. Arch Dis Child. 1999;81 (4):295-300. https://doi.org/10.1136/adc.81.4.295

12. Cnossen MH, Aarsen FK, Akker SL, Danen R, Appel IM, Steyerberg EW, et al. Paediatric arterial ischaemic stroke: functional outcome and risk factors. Dev Med Child Neurol. 2010;52(4):394-9. https://doi.org/10.1111/j.1469-8749.2009.03580.x
13. Grelli KN, Gindville MC, Walker CH, Jordan LC. Association of blood pressure, blood glucose, and temperature with neurological outcome after childhood stroke. JAMA Neurol. 2016;73(7):829-35. https://doi.org/10.1001/jamaneurol.2016.0992

14. Sébire G, Fullerton H, Riou E, Veber G. Toward the definition of cerebral arteriopathies of childhood. Curr Opin Pediatr. 2004;16(6):617-22. https://doi.org/10.1097/01.mop.0000144441.29899.20

15. Ichord RN, Benedict SL, Chan AK, Kirkham FJ, Nowak-Göttl U. Paediatric cerebral sinovenous thrombosis: Findings of the International Paediatric Stroke Study. Arch Dis Child. 2015;100(2):174-9. https://doi.org/10.1136/archdischild-2014-306382

16. Bigi S, Fischer U, Wehrli E, Mattle HP, Boltshauser E, Bürki S et al. Acute ischemic stroke in children versus young adults. Ann Neurol. 2011;70(2):245-54. https://doi.org/10.1002/ana.22427

17. Buuren LM, Aa NE, Dekker HC, Vermeulen RJ, Nieuwenhuizen O, Schooneveld MM et al. Cognitive outcome in childhood after unilateral perinatal brain injury. Dev Med Child Neurol. 2013;55(10):934-40. https://doi.org/10.1111/dmcn.12187

18. Steinlin M, Roellin K, Schroth G. Long-term follow-up after stroke in childhood. Eur J Pediatr. 2004;163(4-5):245-50. https://doi.org/10.1007/s00431-003-1357-x

19. Studer M, Boltshauser E, Capone Mori A, Datta A, Fluss J, Mercati D, et al. Factors affecting cognitive outcome in early pediatric stroke. Neurology. 2014;82(9):784-92. https://doi.org/10.1212/WNL.0000000000000162

20. Gordon AL, Ganesan V, Towell A, Kirkham FJ. Functional outcome following stroke in children. J Child Neurol. 2002;17(6):429-34. https://doi.org/10.1177/088307380201700606

21. Schroll H, Hamker FH. Computational models of basal-ganglia pathway functions: focus on functional neuroanatomy. Front Syst Neurosci. 2013;7(DEC):122. https://doi.org/10.3389/fnsys.2013.00122

22. Greene DJ, Laumann TO, Dubis JW, Ihnen SK, Neta M, Power JD et al. Developmental changes in the organization of functional connections between the basal ganglia and cerebral cortex.J Neurosci. 2014;34(17):5842-54. https://doi.org/10.1523/JNEUROSCI.3069-13.2014

23. Johnston MV. Clinical disorders of brain plasticity. Brain Dev. 2004;26(2):73-80. https://doi.org/10.1016/S0387-7604(03)00102-5

24. Christerson S, Strömberg B. Stroke in Swedish children II: long-term outcome. Acta Paediatr. 2010;99(11):1650-6. https://doi.org/10.1111/j.1651-2227.2010.01948.x

25. Goldenberg NA, Bernard TJ, Fullerton HJ, Gordon A, Veber G. Antithrombotic treatments, outcomes, and prognostic factors in acute childhood-onset arterial ischaemic stroke: a multicentre, observational, cohort study. Lancet Neurol. 2009;8(12):1120-7. https://doi.org/10.1016/S1474-4422(09)70241-8 